\title{
Исследование влияния переходного слоя нанопористого кремния на атомное и электронное строение, а также оптические свойства

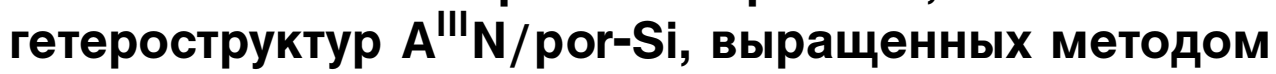 плазменно-активированной молекулярно-пучковой эпитаксии
}

\author{
(С) П.В. Середин ${ }^{1,2}$, А.С. Леньшин ${ }^{1}$, Д.С. Золотухин ${ }^{1}$, Д.Л. Голощапов ${ }^{1}$, А.М. Мизеров ${ }^{3}$, \\ И.Н. Арсентьев ${ }^{4}$, А.Н. Бельтюков ${ }^{5}$ \\ ${ }^{1}$ Воронежский государственный университет, \\ 394006 Воронеж, Россия \\ ${ }^{2}$ Уральский федеральный университет им. первого Президента России Б.Н. Ельцина, \\ 620002 Екатеринбург, Россия \\ ${ }^{3}$ Санкт-Петербургский национальный исследовательский Академический университет \\ Российской академии наук, \\ 194021 Санкт-Петербург, Россия \\ ${ }^{4}$ Физико-технический институт им. А.Ф. Иоффе Российской академии наук, \\ 194021 Санкт-Петербург, Россия \\ ${ }^{5}$ Удмурдский федеральный исследовательский центр Уральского отделения Российской академии наук, \\ 426000 Ижевск, Россия \\ E-mail: paul@phys.vsu.ru
}

Поступила в Редакцию 12 февраля 2019 г.

В окончательной редакции 26 февраля 2019 г.

Принята к публикации 26 февраля 2019 г.

\begin{abstract}
Показано влияние использования переходного нанопористого подслоя кремния por-Si на морфологические, физические и структурные свойства наноколончатых структур $\operatorname{In}_{x} \mathrm{Ga}_{1-x} \mathrm{~N}$, полученных методом плазменноактивированной молекулярно-пучковой эпитаксии на монокристаллических $\operatorname{Si}(111)$ подложках. Комплексом структурно-спектроскопических методов анализа изучено электронное строение выращенных гетероструктур, морфология и оптические свойства, а также установлены взаимосвязи между ними. Показано, что использование подслоя por-Si позволяет получить более однородное распределение диаметров наноколонн $\mathrm{In}_{x} \mathrm{Ga}_{1-x} \mathrm{~N}$, равно как увеличить интенсивность фотолюминесценции последних.
\end{abstract}

Ключевые слова: нитрид галлия, кремниевая технология, фотолюминесценция, нуклеация, плазменноактивированная молекулярно-пучковая эпитаксия.

DOI: 10.21883/FTP.2019.07.47882.9084

\section{1. Введение}

В настоящее время большой интерес вызывают гетероструктуры (ГС) на основе системы материалов $(\mathrm{Al}, \mathrm{In}, \mathrm{Ga}) \mathrm{N}$, которая используется как для изготовления радиационно-стойких, высокотемпературных транзисторов с высокой подвижностью электронов (НЕMT) [1], так и для оптоэлектронных приборов ультрафиолетового диапазона [2]. Однако в силу отсутствия коммерчески доступных гомоэпитаксиальных подложек ростовые процессы проводятся на гетероэпитаксиальных подложках $c-\mathrm{Al}_{2} \mathrm{O}_{3}, 6 \mathrm{H}-\mathrm{SiC}$ и $\mathrm{Si}(111)$, сильно рассогласованных со слоями по параметрам решетки и коэффициентам температурного расширения [3]. В силу низкой стоимости и широкого распространения кремниевой технологии кремниевые подложки являются наиболее перспективными для получения приборных ГС на основе системы материалов (In, Ga)N, однако они являются и наиболее „сложными“ для формирования гетероэпитаксиальных слоев достаточного для приборных применений качества.
В настоящее время актуальными проблемами при формировании эпитаксиальных слоев (In, Ga)N являются проблема растрескивания толстого слоя при охлаждении от температуры роста до комнатной из-за различия в коэффициентах температурного расширения, проблема генерации большого количества дислокаций несоответствия, существенно ухудшающих приборные качества $\Gamma C$, а также хорошо известная проблема протравливания поверхности кремниевой подложки жидким галлием.

Одним из методов решения данных проблем, наряду с использованием традиционных буферных слоев AlN, является формирование переходных буферных слоев в виде наноколонн. Благодаря высокому кристаллическому совершенству, а также наличию свободной поверхности буферные слои на основе наноколонн позволяют снять генерируемые напряжения растяжения, а также остановить распространение прорастающих дислокаций.

В наших предыдущих работах [4-8] мы обратили внимание на еще один подход, который в совокупности с использованием наноколончатой морфологии слоя позволяет более эффективно интегрировать полупровод- 
никовые соединения $\mathrm{A}^{\mathrm{III}} \mathrm{N}$ с кремнием. В данном подходе предложено использовать переходный буферный слой нанопористого кремния (por-Si), сформированный непосредственно на подложке $c$-Si. Было показано, что использование por-Si задает преимущественную ориентацию роста наноколонн $\operatorname{In}_{x} \mathrm{Ga}_{1-x} \mathrm{~N}$ ближе к направлению ориентации $\mathrm{Si}(111)$, а также позволяет получить наноколонны $\operatorname{In}_{x} \mathrm{Ga}_{1-x} \mathrm{~N}$ с более высокой кристаллографической однородностью и унифицированным по всей поверхности латеральным размером наноколонн $\sim 40$ нм. Рост наноколонн $\operatorname{In}_{x} \mathrm{Ga}_{1-x} \mathrm{~N}$ на пористом слое por-Si приводит к снижению величин компонент тензора деформации $\varepsilon_{x x}$ и $\varepsilon_{z z}$, а также плотности краевых и винтовых дислокаций по сравнению с аналогичными величинами для наноколонн $\operatorname{In}_{x} \mathrm{Ga}_{1-x} \mathrm{~N}$, выращенных на $c$-Si [5]. Хорошо известно, что финальные свойства наногетероструктур на основе интегрированных соединений $\mathrm{A}^{\mathrm{III}} \mathrm{N}$ с кремнием и наноколончатой морфологией эпитаксиального слоя весьма сильно зависят от состояния их поверхности и ее морфологии, а также от условий ее обработки.

Поэтому в нашей новой работе мы продолжаем исследование влияния переходного слоя нанопористого кремния на атомное и электронное строение, а также оптические свойства гетероструктур $\mathrm{A}^{\mathrm{III}} \mathrm{N} /$ por-Si, выращенных методом плазменно-активированной молекулярнопучковой эпитаксии.

\section{2. Эксперимент}

Для исследования влияния буферного слоя por-Si на особенности атомного и электронного строения гетероструктур на основе соединений (In, Ga)N/Si с наноколончатой морфологией пленки в едином эпитаксиальном процессе была выращена серия тестовых образцов. Были получены два типа образцов гетероструктур: $(\mathrm{In}, \mathrm{Ga}) \mathrm{N} / \mathrm{Si}(111)$ (образец A1) и $(\mathrm{In}, \mathrm{Ga}) \mathrm{N} /$ por-Si/Si $(111)$ (образец А2).

Слои пористого кремния ( 100 нм) были получены электрохимическим травлением пластин монокристаллического кремния КДБ с удельным сопротивлением 5 Ом · см и ориентацией (111) в растворе плавиковой кислоты по уже отработанной нами методике [7,9]. Все подложки были подвергнуты процедуре очистки по методу Шираки [10] и отожжены в ростовой камере при температуре $820^{\circ} \mathrm{C}$. Выращивание образцов А1 и А2 с наноколончатой морфологией пленки осуществлялось методом молекулярно-пучковой эпитаксии с плазменной активацией азота (МПЭ ПА) на установке промышленного типа Veeco Gen 200 на подложках, прошедших предварительную химическую подготовку по методу Шираки. Удаление защитного слоя оксида кремния с подложек осуществлялось во время их отжига в ростовой камере при температуре подложки $T_{s}=850^{\circ} \mathrm{C}$ в течение 30 мин. Слой $\operatorname{In}_{x} \mathrm{Ga}_{1-x} \mathrm{~N}$ толщиной $\sim 150$ нм выращивался при постоянных значениях температуры под- ложки $T_{s}=400^{\circ} \mathrm{C}$ в единичных стехиометрических условиях роста при равных соотношениях потоков металлов третьей группы $\left(\mathrm{F}_{\mathrm{III}}=\mathrm{F}_{\mathrm{Ga}}+\mathrm{F}_{\mathrm{In}}\right)$ и активированного азота, $\mathrm{F}_{\mathrm{III}} \approx \mathrm{F}_{\mathrm{N}} \approx 0.06 \mathrm{мкм/ч,} \mathrm{где} \mathrm{поток} \mathrm{индия} \mathrm{состав-}$ лял $\mathrm{F}_{\mathrm{In}} \approx 0.02 \mathrm{ML} / \mathrm{c}$, поток галлия $-\mathrm{F}_{\mathrm{Ga}} \approx 0.04 \mathrm{ML} / \mathrm{c}$ (ML - монослой).

Ростовой процесс контролировался с помощью методов лазерной рефлектометрии, а также анализа картин дифракции in situ отраженных быстрых электронов (ДОБЭ).

Микроскопические исследования качества гетероинтерфейсов были выполнены на электронном микроскопе Libra 120 Carl Zeiss. Изучение морфологии поверхности проводили с использованием сканирующего зондового микроскопа Femtoscan-001 NT MDT в режиме атомносиловой микроскопии (АСM).

Спектры фотолюминесценции (PL) гетероструктур получены при комнатной температуре на установке фотолюминесценции и оптического отражения Accent RPM Sigma (Accent Optical Technologies, CША), при возбуждении лазером с длиной волны 266 нм и интенсивностью излучения $\sim 3 \mathrm{MBT} / \mathrm{cm}^{2}$.

Исследования образцов методом рентгеновской фотоэлектронной спектроскопии (XPS) были выполнены на лабораторном спектрометре фирмы SPECS, возбуждение $\mathrm{Mg} K_{\alpha}$. Анализ состава образцов композитов указанным методом проводился как в поверхностных слоях толщиной $\sim 1$ нм, так и на различной глубине, задаваемой временем травления образца. Травление поверхности в течение 30 с осуществлялось ионами аргона с энергией 4 кэВ, плотность ионного тока составляла $30 \mathrm{м \kappa A} / \mathrm{cm}^{2}$, скорость травления образцов 1.5-2.5 нм/мин. Таким образом, глубина анализа образцов данной методикой была в пределах $\sim(1-2)$ нм. При обработке результатов измерений для вычитания и определения линии фона были использованы алгоритмы, предложенные Ширли [11]. При определении энергий связи остовных уровней элементов гетероструктуры в качестве реперной линии была использована линия $\mathrm{C} 1 \mathrm{~s}$ естественных углеводородных загрязнений поверхности любого образца, не подвергнутого специальной очистке, приведенная к энергии связи $E_{b}[\mathrm{C} 1 s]=285$ эВ. Идентификация остовных уровней элементов и их химического состояния проводилась с использованием базы данных рентгеновских фотоэлектронных спектров Национального института стандартов США [12].

\section{3. Результаты}

Как уже было показано в наших предыдущих работах $[4,5]$, с использованием метода молекулярнопучковой эпитаксии с плазменной активацией азота на подложках $\mathrm{Si}(111)$ и por-Si(111) были получены гетероструктуры с наноколончатой морфологией пленки $\mathrm{In}_{x} \mathrm{Ga}_{1-x} \mathrm{~N}$ с вюрцитной симметрией кристаллической решетки. 


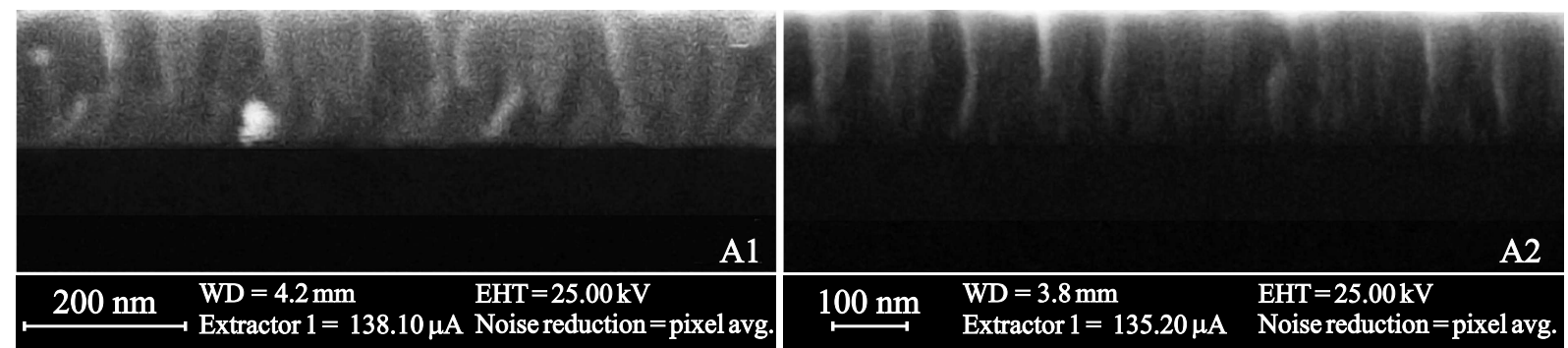

Рис. 1. СЭМ-изображения сколов ГС.
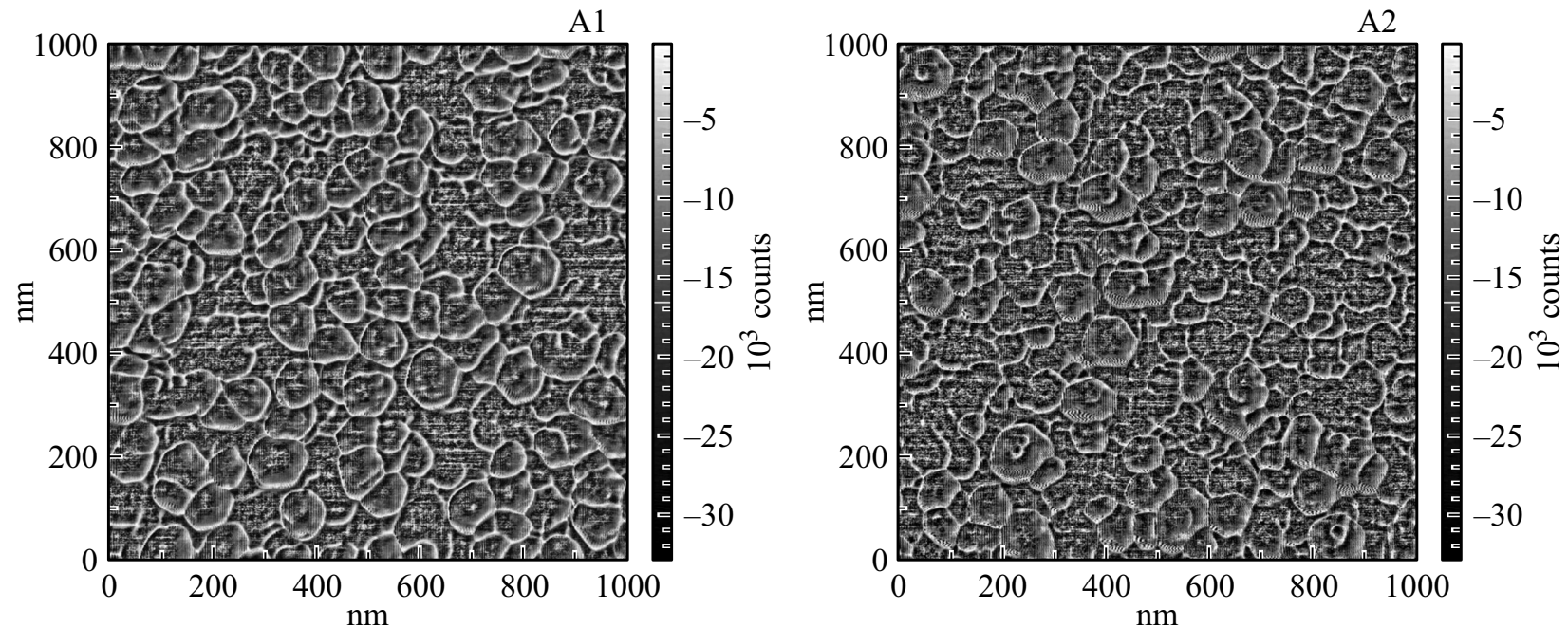

Рис. 2. Фазовый контраст образцов, полученный из анализа АСМ-изображений поверхности.
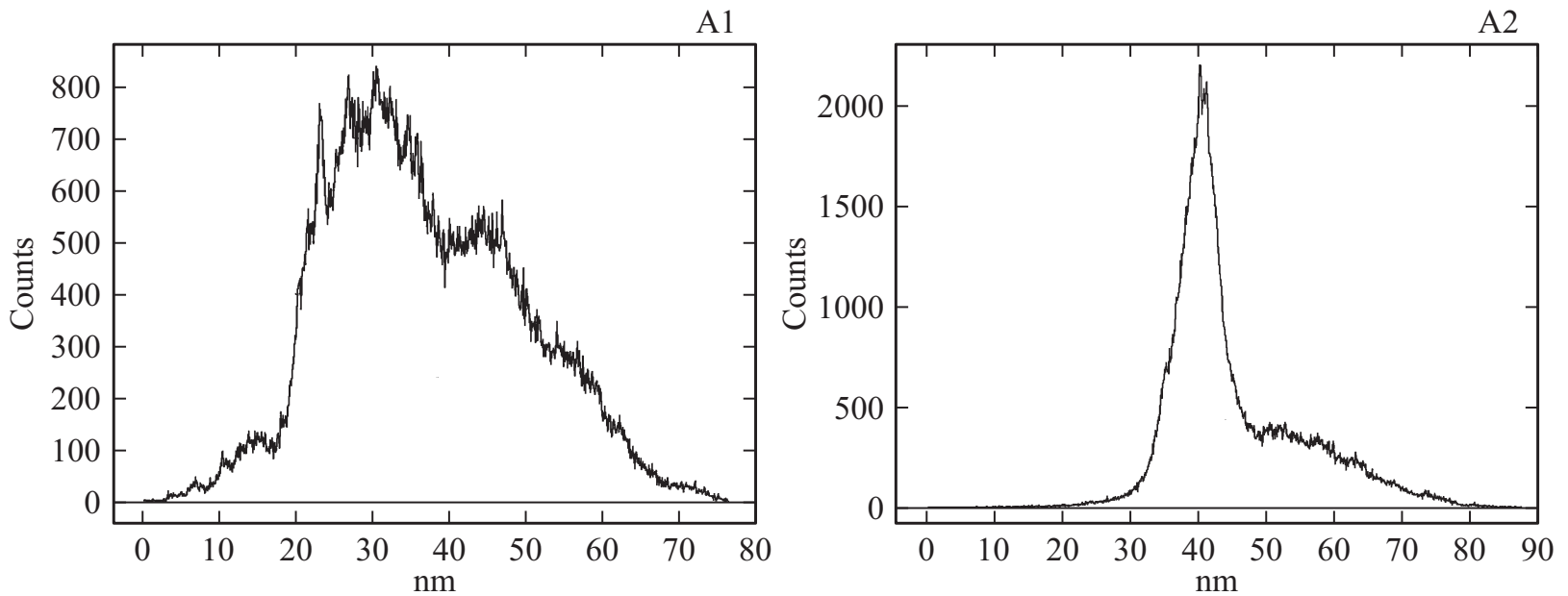

Рис. 3. Гистограммы распределения латеральных размеров неоднородностей на поверхностях образцов.

На рис. 1 представлены полученные методом сканирующей электронной микроскопии (СЭМ) изображения сколов выращенных ГС. Видно, что гетерограница $(\mathrm{In}, \mathrm{GaN})-\mathrm{Si}$ - резкая и гладкая для всех образцов, что свидетельствует об успешном подавлении процессов травления жидким $\mathrm{Ga}$ подложек $\mathrm{Si}(111)$. Можно отметить, что для образца А2 более ярко выражена наноколончатая структура слоя.
Исследование образцов А1 и А2 методом АСМ в режиме фазового контраста (см. рис. 2) показало, что на поверхности гетероструктур обоих типов присутствует лишь одна фаза - твердый раствор $\operatorname{In}_{x} \mathrm{Ga}_{1-x} \mathrm{~N}$ в форме наноколонн. Анализ результатов атомносиловой микроскопии с использованием специализированного программного обеспечения NOVA позволил нам охарактеризовать латеральные размеры наноколонн 


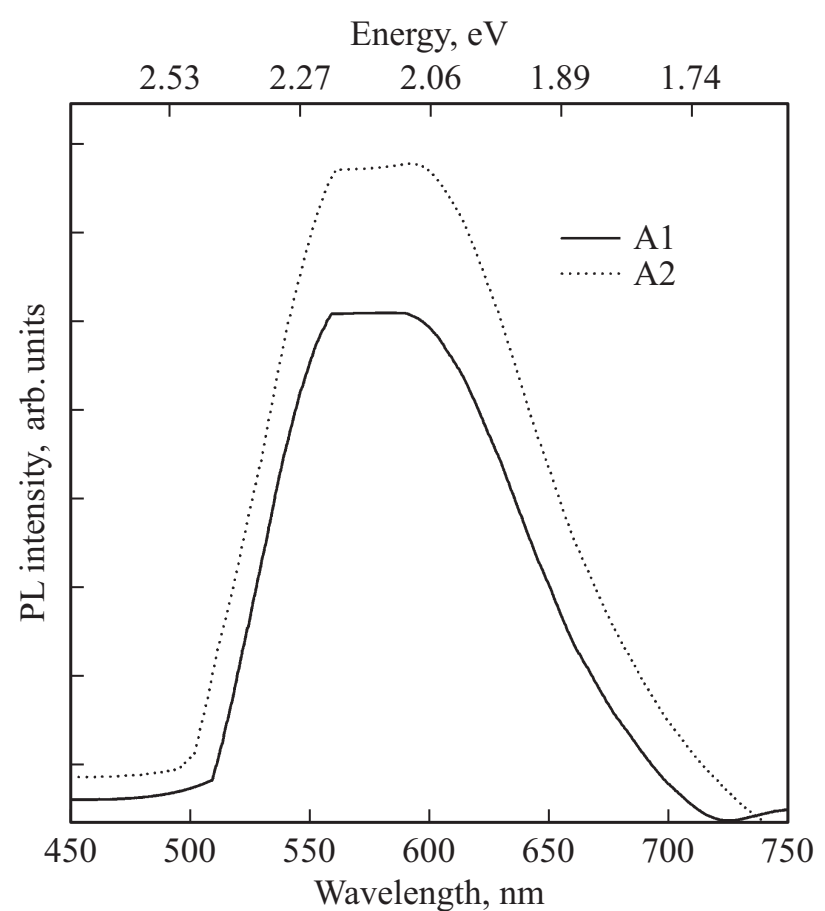

Рис. 4. Спектры фотолюминесценции (PL) образцов.
$\mathrm{In}_{x} \mathrm{Ga}_{1-x} \mathrm{~N}$, сформированных на подложках двух типов. На рис. 3 приведены гистограммы распределения латеральных размеров наноколонн $\operatorname{In}_{x} \mathrm{Ga}_{1-x} \mathrm{~N}$, построенные по результатам анализа АСМ-изображений поверхности. Экспериментальные данные показывают, что на поверхности образца А2 наблюдаются наноколонны с более унифицированным диаметром по сравнению с наноколоннами, сформированными на традиционной подложке $\mathrm{Si}(111)$. Рост эпитаксиальной пленки $\operatorname{In}_{x} \mathrm{Ga}_{1-x} \mathrm{~N}$ c развитой наноколончатой морфологией на подложках $\mathrm{Si}$ с переходным пористым слоем однозначно должен отразиться на оптических свойствах интегрированных гетероструктур, а в частности на фотолюминесценции от эпитаксиальной пленки. Для этого нами были получены спектры фотолюминесценции образов А1 и А2, которые представлены на рис. 4 без нормировки. Хорошо видно, что в спектрах присутствует единственный максимум в области длин волн 500-700 нм, соответствующий излучению зона-зона от твердого раствора $\operatorname{In}_{x} \mathrm{Ga}_{1-x} \mathrm{~N}$. При этом интенсивность фотолюминесценции эпитаксиального слоя $\operatorname{In}_{x} \mathrm{Ga}_{1-x} \mathrm{~N}$, выращенного на подложке с подслоем por-Si (образец А2), выше на $~ 25 \%$ интенсивности образца А1.
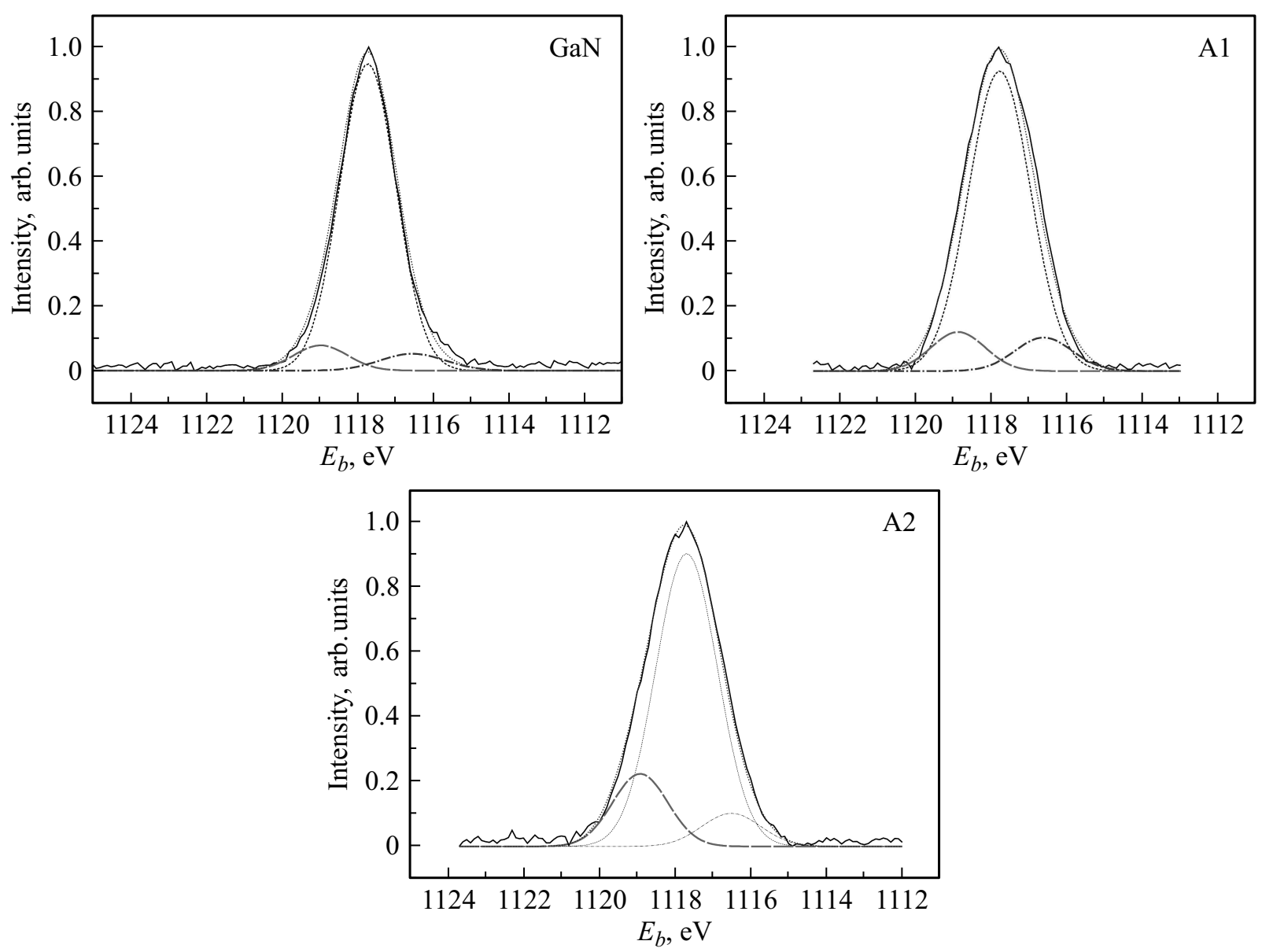

Pис. 5. Спектры Ga 2p 3/2 эталонного образца $\mathrm{GaN}$ и образцов $\mathrm{A} 1, \mathrm{~A} 2$. 

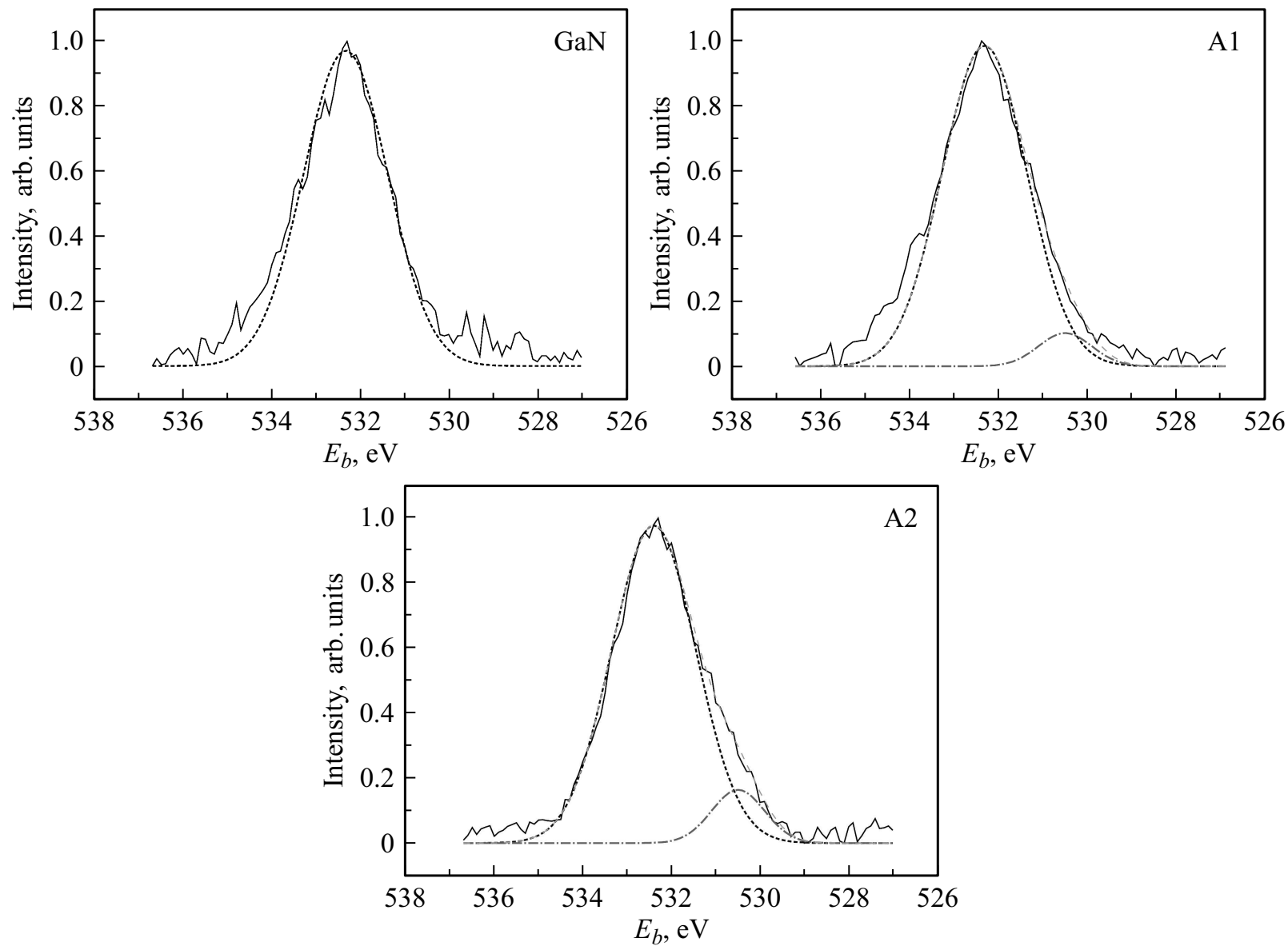

Рис. 6. Спектры O $1 s$ эталонного образца $\mathrm{GaN}$ и образцов $\mathrm{A} 1$ и $\mathrm{A} 2$.
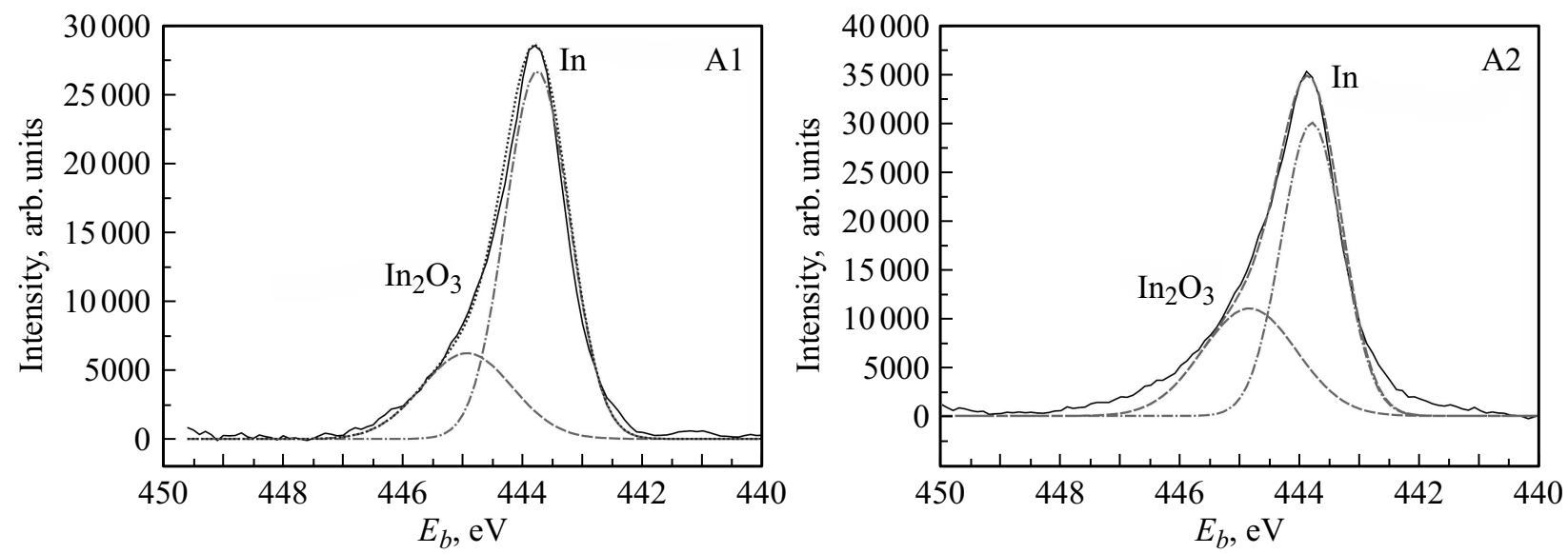

Рис. 7. Спектры In $3 d_{5 / 2}$ образцов $\mathrm{A} 1$ и $\mathrm{A} 2$.

Как показано в работе [13], положение максимума интенсивности спектров фотолюминесценции для твердых растворов $\operatorname{In}_{x} \mathrm{Ga}_{1-x} \mathrm{~N}$ имеет непрямую связь с шириной запрещенной зоны и составом твердого раствора. Из положения пиков (для А1 и А2 длины волны 588 и 592 нм) были рассчитаны концентрации индия $x(\mathrm{~A} 1) \approx x(\mathrm{~A} 2) \approx 0.3$. Полученные результаты хо- рошо согласуются с уже имеющимися у нас данными рентгеновской дифракции.

Как уже было сказано выше, наличие высокоразвитой, а зачастую и химически активной поверхности, а также ее состав весьма сильно сказываются на электронном строении гетероструктур, что находит в дальнейшем свое отражение в финальных свойствах формируемо- 
го оптоэлектронного устройства. Поэтому электронные свойства образцов были изучены методом фотоэлектронной спектроскопии.

C применением метода XPS, который позволяет исследовать химический состав поверхности, мы также уточнили концентрации атомов в образцах $\operatorname{In}_{x} \mathrm{Ga}_{1-x} \mathrm{~N}$, выращенных на кристаллическом и пористом кремнии. В качестве эталона использовалась пленка монокристаллического $\mathrm{GaN}$ толщиной 3 мкм, полученная методом МПЭ на подложке $\mathrm{Al}_{2} \mathrm{O}_{3}$. XPS-спектры остовных уровней $\mathrm{Ga} 2 p_{3 / 2}, \mathrm{O} 1 s$ и In $3 d_{5 / 2}$ приведены на рис. 5-7.

На рис. 5 представлены XPS-кривые Ga $2 p_{3 / 2}$ исследованных образцов А1 и А2. Спектры Ga $2 p$ образцов гетероструктур на кремнии и на пористом кремнии имеют бо́льшую FWHM, чем спектр „эталонного“ образца $\mathrm{GaN}$. При этом интенсивность спектра образца А2 в области больших энергий связи выше, чем интенсивность спектра образца А1. Разложение спектров $\mathrm{Ga} 2 p$ на компоненты показывает, что „эталонный“ образец действительно в основном представляет собой $\mathrm{GaN}$ - основной пик соответствует энергии связи $E_{b}=117.8$ эВ, также возможно наличие небольшого количества металлического галлия (116.5 эВ) и оксида $\mathrm{Ga}_{2} \mathrm{O}_{3}$ (119 эВ). Для образцов A1 и A2, выращенных на кремнии, также основным является пик, соответствующий $\mathrm{GaN}$, однако вклад боковых компонент растет. При этом в спектре образца А2 область, соответствующая $\mathrm{Ga}_{2} \mathrm{O}_{3}$, является наиболее выраженной.

Сравнительный анализ спектров образцов О $1 s$ (рис. 5) показал, что со стороны меньших энергий связи спектры образцов как на кристаллическом, так и на пористом кремнии уширены по сравнению с эталоном. Разложение O $1 s$-спектра XPS на компоненты показывает присутствие кислорода на поверхности образцов в 2 зарядовых состояниях, более интенсивная компонента с $E_{b}=532.5$ эВ (адсорбированный кислород) и менее интенсивная с $E_{b}=530.5$ эВ (кислород в связи с металлом). Согласно базе данных NIST, эта энергия связи характерна для оксидов $\mathrm{Ga}_{2} \mathrm{O}_{3}$ или $\mathrm{In}_{2} \mathrm{O}_{3}$. При этом в спектре эталонного образца менее интенсивная компонента с $E_{b}=530.5$ эВ практически не наблюдается, что хорошо согласуется с данными анализа спектров $\mathrm{Ga} 2 p$ образцов.

Содержание In и фазовый состав в образцах $\mathrm{In}_{x} \mathrm{Ga}_{1-x} \mathrm{~N}$ были уточнены по форме, положению и интенсивности XPS-пиков In $3 d_{5 / 2}$ (рис. 6). Разложение спектров на компоненты показывает, что In в образцах находится преимушественно в форме нитрида (пик с $E_{b}=443.8-444$ эВ), однако при этом заметен существенный вклад от оксида $\mathrm{In}_{2} \mathrm{O}_{3}\left(E_{b}=444.7-444.9\right.$ эВ). Как показано в работе [14], содержание индия в пленке $\mathrm{In}_{x} \mathrm{Ga}_{1-x} \mathrm{~N}$ может быть рассчитано на основе следующего соотношения:

$$
X_{\mathrm{In}}=\frac{I_{\mathrm{In} 3 d 5} / F_{\mathrm{In} 3 d 5}}{\left(I_{\operatorname{In} 3 d 5} / F_{\operatorname{In} 3 d 5}+I_{\mathrm{Ga} 2 p 3} / F_{\mathrm{Ga} 2 p 3}\right)}
$$

где $I$ - интегральная интенсивность фотоэлектронных максимумов соответствующих линий в спектре, а $F-$ фактор чувствительности $\left(F_{\mathrm{Ga} 2 p 3}=2.75\right.$ и $\left.F_{\mathrm{In} 3 d 5}=4.53\right)$. С использованием формулы (1) и с учетом данных, представленных на рис. 5,6, были рассчитаны значения концентрации атомов In, $x=0.32$ в A1 и 0.34 в A2, что хорошо согласуется с расчетными данными, полученными из анализа спектров фотолюминесценции, и согласуется с уже имеющимися данными рентгеновской дифракции из наших предыдущих работ.

Анализируя полученные методом фотоэлектронной спектроскопии результаты, мы считаем, что появление оксидов металлов на поверхности образцов, наиболее вероятно, происходит вследствие хранения обоих образцов в атмосферных условиях, приводивших к постепенному окислению, а не является побочным результатом технологических операций при МПЭ. Содержание оксидов In и Ga для образца A2, выращенного на пористом кремнии, несколько выше, чем для образца, выращенного на кристаллическом кремнии. Этот факт, скорее всего, связан с различиями в морфологии поверхности образцов, а именно в меньшем разбросе по размерам неоднородностей и большей удельной площади поверхности образцов, выращенных на пористой подложке.

\section{4. Заключение}

Рост наноколонок $\operatorname{In}_{x} \mathrm{Ga}_{1-x} \mathrm{~N}$ на нанопористом буферном слое por-Si имеет ряд преимуществ по сравнению с ростом на $c$-Si. Как показал анализ данных атомно-силовой и растровой электронной микроскопии образцов $\operatorname{In}_{x} \mathrm{Ga}_{1-x} \mathrm{~N} / c-\mathrm{Si}$ и $\operatorname{In}_{x} \mathrm{Ga}_{1-x} \mathrm{~N} /$ por-Si, слой, сформированный на подложке por-Si, обладает большей однородностью распределения диаметров наноколонн, что в свою очередь приводит к увеличению свободной поверхности материала. Наличие большой площади свободной поверхности приводит к повышению коэффициента извлечения света из ГС, что, по-видимому, ведет к значительному $(\sim 25 \%)$ возрастанию интегральной интенсивности спектра фотолюминесценции образца $\mathrm{In}_{x} \mathrm{Ga}_{1-x} \mathrm{~N} /$ por-Si. Поверхность эпитаксиальных пленок $\operatorname{In}_{x} \mathrm{Ga}_{1-x} \mathrm{~N}$ с наноколончатой морфологией покрыта металлооксидными фазами. При этом содержание оксидов In и Ga в образце, выращенном на пористом кремнии, несколько выше, чем для образца, выращенного на кристаллическом кремнии, что связано с различиями в морфологии поверхности образцов.

Таким образом, использование „податливых“ подложек por-Si является эффективным подходом для формирования полупроводниковых приборных гетероструктур на основе системы материалов (In, Ga)N методом МПЭ ПА.

\section{Финансирование работы}

Работа выполнена при финансовой поддержке гранта Президента РФ МД-42.2019.2 и постановления № 211 
Правительства Российской Федерации. В части диагностики интегрированных структур работа поддержана грантом № 11.4718.2017/8.9 Министерства науки и высшего образования Российской Федерации в рамках Государственного задания вузам в сфере научной деятельности на 2017-2019 гг. и постановления № 211 Правительства Российской Федерации, контракт № 02.А03.21.0006.

Ростовые эксперименты проводились в рамках выполнения государственного задания Министерства науки и высшего образования Российской Федерации № $16.9789 .2017 /$ БЧ.

Работа в части исследований управления морфологией и составом монолитной и пористой подложек, выполнена при финансовой поддержке ФТИ им. А.Ф. Иоффе.

\section{Конфликт интересов}

Авторы заявляют, что у них нет конфликта интересов.

\section{Список литературы}

[1] U.K. Mishra, L. Shen, T.E. Kazior, Y.F. Wu. IEEE Proc., 96, 287 (2008).

[2] M. Shatalov, W. Sun, R. Jain, A. Lunev, X. Hu, A. Dobrinsky, Y. Bilenko, J. Yang, G.A. Garrett, L.E. Rodak. Semicond. Sci. Technol., 29, 084007 (2014).

[3] S.A. Kukushkin, A.V. Osipov, V.N. Bessolov, B.K. Medvedev, V.K. Nevolin, K.A. Tcarik. Rev. Adv. Mater. Sci., 17, 1 (2008).

[4] P.V. Seredin, D.L. Goloshchapov, A.S. Lenshin, D.S Zolotukhin. Phys. E: Low-Dim. Syst. Nanostructures., 104, 101 (2018).

[5] P.V. Seredin, D.L. Goloshchapov, D.S. Zolotukhin, M.A. Kondrashin, A.S. Lenshin, Y.Y. Khudyakov, A.M. Mizerov, I.N. Arsentyev, A.N. Beltiukov, H. Leiste, M. Rinke. Semiconductors, 52, 1653 (2018).

[6] P.V. Seredin, V.M. Kashkarov, I.N. Arsentyev, A.D. Bondarev, I.S. Tarasov. Physica B, 495, 54 (2016).

[7] P.V. Seredin, A.S. Lenshin, D.L. Goloshchapov, A.N. Lukin, I.N. Arsentyev, A.D. Bondarev, I.S. Tarasov. Semiconductors, 49, 915 (2015).

[8] P.V. Seredin, A.S. Lenshin, V.M. Kashkarov, A.N. Lukin, I.N. Arsentyev, A.D. Bondarev, I.S. Tarasov. Proc. Mater. Sci. Semicond., 39, 551 (2015).

[9] E.P. Domashevskaya, V.M. Kashkarov, P.V. Seredin, V.A. Terekhov, S.Y. Turishchev, I.N. Arsentyev, V.P. Ulin. Mater. Sci. Engin. B, 147, 144 (2008).

[10] A.S. Lenshin, V.M. Kashkarov, P.V. Seredin, B.L. Agapov, D.A. Minakov, V.N. Tsipenyuk, E.P. Domashevskaya. Techn. Phys., 59, 224 (2014).

[11] D.A. Shirley. Phys. Rev. B, 5, 4709 (1972).

[12] NIST X-ray Photoelectron Spectroscopy (XPS) Database. https://srdata.nist.gov/xps/

[13] K.P. O’Donnel, J.F.W. Mosselmans, R.W. Martin, S. Pereira, M.E. White. J. Phys.: Condens. Mater., 13, 6977 (2001).

[14] Z.L. Fang, Q.F. Li, X.Y. Shen, J.F. Cai, J.Y. Kang, W.Z. Shen. J. Appl. Phys., 115, 043514 (2014).
Comprehensive study of nanoporous $\mathrm{Si}$ layer influence on atomic and electron structure and optical properties of $A^{\prime \prime \prime} \mathrm{N} /$ por-Si heterostructures grown by plasma assisted molecular beam epitaxy

\author{
P.V. Seredin ${ }^{1,2}$, A.S. Lenshin ${ }^{1}$, D.S. Zolotukhin ${ }^{1}$, \\ D.L. Goloshchapov ${ }^{1}$, A.M. Mizerov ${ }^{3}$, \\ I.N. Arsentyev ${ }^{4}$, A.N. Beltyukov ${ }^{5}$ \\ ${ }^{1}$ Voronezh State University, \\ 394006 Voronezh, Russia \\ 2 Ural Federal University, \\ 620002 Ekaterinburg, Russia \\ ${ }^{3}$ Saint-Petersburg National Research Academic \\ University, Russian Academy of Sciences, \\ 194021 St. Petersburg, Russia \\ ${ }^{4}$ loffe institute, \\ 194021 St. Petersburg, Russia \\ 5 Udmurt Federal Research Center, \\ Ural Branch of Russian Academy of Sciences, \\ 426000 Izhevsk, Russia
}

\begin{abstract}
This paper reports about influence of a nanoporous $\mathrm{Si}$ buffer layer on morphological, physical and structural properties of the $\operatorname{In}_{x} \mathrm{Ga}_{1-x} \mathrm{~N}$ layer with nanocolumnar morphology of the surface, grown by plasma assisted molecular beam epitaxy on the traditional $\mathrm{Si}(111)$ substrates. By means of various structural and spectroscopy methods electronic structure, morphology of the surface and optical properties of grown heterostructures were studied. We showed that usage of por-Si sub-layer helps to achieve more isotropic InGaN nanocolumns diameter distribution as well as to increase photoluminescence intensity up to $25 \%$.
\end{abstract}

